\title{
A Comparison of Alkaline and Organosolv Lignin Extraction Methods from Coconut Husks as an Alternative Material for Green Applications
}

\author{
Nur Hanis Abd Latif, ${ }^{\mathrm{a}}$ Nicolas Brosse, ${ }^{\mathrm{b}, *}$ Isabelle Ziegler-Devin, ${ }^{\mathrm{b}}$ Laurent Chrusiel, ${ }^{\mathrm{b}}$ \\ Rokiah Hashim, ${ }^{\mathrm{c}}$ and M. Hazwan Hussin ${ }^{\mathrm{a}, *}$ \\ Effects of alkaline (kraft and soda) and organosolv pulping were evaluated \\ relative to the structural properties of lignin isolated from coconut husk \\ $(\mathrm{CH})$ biomass. The various types of functional groups within the isolated \\ lignin samples were characterized and compared using a variety of \\ complementary analyses including Fourier-transform infrared (FTIR) \\ spectroscopy, nuclear magnetic resonance (NMR) spectroscopy, gel \\ permeation chromatography (GPC), and high-performance liquid \\ chromatography (HPLC). All isolated $\mathrm{CH}$ lignin samples contained a \\ significant quantity of non-condensed guaiacyl-type $(\mathrm{G})$ and syringyl-type \\ (S) units but a lesser amount of p-hydroxyphenyl $(\mathrm{H})$ units, as \\ demonstrated and supported by previous research. The alkaline $\mathrm{CH}$ lignin \\ produced lignin with higher molecular weight $\left(M_{\mathrm{w} \mathrm{SL}}: 959 \mathrm{~g} \mathrm{~mol}^{-1}>M_{\mathrm{w} \mathrm{KL}}\right.$ : \\ $\left.769 \mathrm{~g} \mathrm{~mol}^{-1}\right)$ than the organosolv lignin $\left(M_{\mathrm{w} \mathrm{OL}}: 606 \mathrm{~g} \mathrm{~mol}^{-1}\right)$ sample, \\ resulting in smaller fragments and a higher degree of solubility in water or \\ other solvents. Because of significant differences in the physicochemical \\ characteristics of the various lignin polymers, their properties and structure \\ were improved with respect to alternative approaches in lignin-based \\ applications.
}

DOI: 10.15376/biores.17.1.469-491

Keywords: Coconut husk; Alkaline lignin; Organosolv lignin

Contact information: a: Materials Technology Research Group (MaTReC), School of Chemical Sciences, Universiti Sains Malaysia, 11800, Minden, Penang, Malaysia; b: Laboratoire d'Etude et de Recherche sur le MAteriau Bois (LERMAB), Faculte des Sciences et Technologies, Universite de Lorraine, Vandoeuvre-lesNancy, France; c: School of Technology Industrial, Universiti Sains Malaysia, 11800, Minden, Penang, Malaysia; *Corresponding author:mhh@usm.my; nicolas.brosse@univ-lorraine.fr

\section{INTRODUCTION}

Many researchers have become interested in turning abundantly available biomass waste into bio-based products as a way to help mitigate the rise in global warming induced by non-renewable petroleum/fossil-based products. Biomass wastes are typically made from agricultural wastes, such as livestock feed, which is left to decompose naturally, and still, others are left unutilized (Johari et al. 2016; Zakaria et al. 2017; Ram and Mondal 2018). In Malaysia, coconut trees (Cocos nucifera L.) are widely cultivated and known for their important use based on their various parts (Kumar 2011; Johari et al. 2016; Saari et al. 2016). According to the Department of Statistics Malaysia in 2020, the highest fruit in terms of self-sufficiency ratio (SSR) and per capita consumption (PCC) from 2015 to 2019 was coconut, which is consumed at a rate of $22.7 \mathrm{~kg}$ per year, followed by other fruits in selected crops (Mahidin 2020). The outer layer of the coconut fruit, known as coconut husk 
$(\mathrm{CH})$ is a major agro-industrial waste produced in developing countries every year that is biodegradable, low in cost, and readily available in large quantities (Kaewdang and Benjakul 2015; Johari et al. 2016; Saari et al. 2016; Ram and Mondal 2018). Coconut husk is composed of $30 \mathrm{wt} \%$ fibre and $70 \mathrm{wt} \%$ pith, which is primarily made up of cellulose (34.9 to 42.3\%), hemicellulose (1.1 to 21.9\%), and a rich amount of lignin (29.8 to 53.5\%) (van Dam et al. 2004; Israel et al. 2011; Jincy et al. 2015; Saari et al. 2016). Furthermore, coconut husk fibre has been investigated for its ethanolic extract effect relative to the gel properties of gelatin (Kaewdang and Benjakul 2015), fuel production (Ram and Mondal 2018), cement material for building applications (Lertwattanaruk and Suntijitto 2015), and performance as adsorbents for the removal of heavy metal ions ( $\mathrm{Hg}$ ) (Johari et al. 2016).

Lignin is a well-researched natural feedstock for industrial applications that is widely studied such as an emulsifiers of catalytic cracking heavy oil (Xu et al. 2011; Upton and Kasko 2016), low-cost lignin carbon fibers manufacture (Baker and Rials 2013), bioplastic (Spiridon et al. 2015), biocomposite (Privas and Navard 2013), polyurethane foam (Luo et al. 2018), and in the production of value-added chemicals. In plants, lignin acts as an adhesive by filling the gaps between cellulose and hemicellulose and binding the lignocellulose matrix together as well as providing strength and stiffness to the cell walls (Qingqing et al. 2019). It is a complex three-dimensional biopolymer composed of three phenylpropanoid monomers: p-coumaryl alcohol (p-hydroxyphenyl, $\mathrm{H}$ units), coniferyl alcohol (guaiacyl, G units), and sinapyl alcohol (syringyl, S units) (Fig. 1) (Jincy et al. 2015; Aziz et al. 2019; Hussin et al. 2019; Latif et al. 2019; Qingqing et al. 2019). Recently, in a cellulose-based polymer electrolyte, $\mathrm{CH}$ lignin was shown to play an important part as a natural plasticizer by improving the ionic conductivity of the solid polymer electrolyte along with the presence of cellulose derivatives (Chua et al. 2020), and it has also been used for dye removal in carbon cryogel beads (Ngadi et al. 2015). Because $\mathrm{CH}$ lignin has a similar phenolic structure to phenol, with potential to cross-link with resins, it has shown a good performance especially in mechanical properties of exterior-grade plywood sheets used in industrial manufacturing (Saari et al. 2016; Aziz et al. 2019; Hussin et al. 2019).

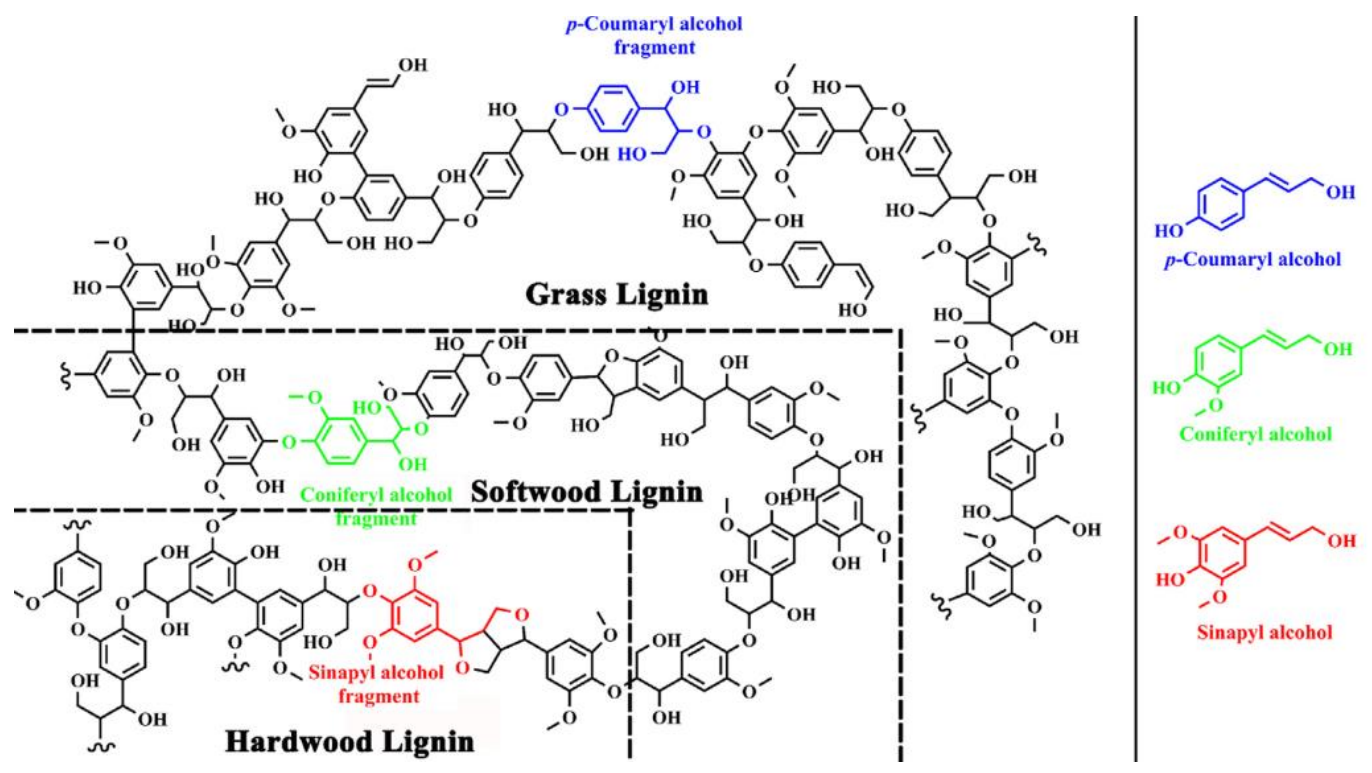

Fig. 1. Lignin structure with the main inter-subunit linkages (Qingqing et al. 2019) 
A separation or pulping process is needed to utilize lignin and process it into highvalue products. The physicochemical characteristics of lignin obtained from alkaline pulping (kraft and soda) and organosolv pulping processes were different (Aziz et al. 2019; Latif et al. 2019). According to the previous studies, the alkaline processes are used to isolate lignin from wood content in the pulp and paper industry (96\% of the market). The breaking down of aryl-ether linkages occurred during alkaline pulping, resulting in the liberation of the lignin fragments as well as their dissolution and condensation reaction. During the condensation procedure, the molecular size of lignin fragments increased because of the conjugate addition of carbanions to quinine methide intermediates (Hussin et al. 2013). Due to the absence of sulfur contents, the soda lignin obtained was much purer than kraft lignin, which also improved its reactivity (Tribot et al. 2019). Previously, organosolv pulping produced more reactive lignin with higher purity, resulting in a lower molecular weight that is mostly soluble in common solvents (Hussin et al. 2013; Latif et al. 2019). Moreover, their structure contains a high proportion of oxidized groups and phenolic hydroxyl groups (such as Hibbert ketones), which facilitates chemical modification and incorporation into polymer formulations (Hussin et al. 2013).

Consequently, the current research aimed to study the structural and physicochemical characteristics of lignin isolated from coconut husk $(\mathrm{CH})$ using various pulping techniques (kraft, soda, and organosolv pulping), as well as its potential as a phenolic substitution for material applications. There have not been several studies contrasting the functionalization of alkaline and organosolv lignin isolated from $\mathrm{CH}$ biomass. The isolated kraft lignin (KL), soda lignin (SL), and organosolv lignin (OL) were characterized using Fourier transform infrared (FTIR) spectroscopy, gel permeation chromatography (GPC) analysis, and ${ }^{13} \mathrm{C}$ - and $2 \mathrm{D}$-heteronuclear single quantum coherence (HSQC) nuclear magnetic resonance (NMR) spectroscopy to investigate any changes in the structure of lignin after undergoing the pulping process. Additionally, thermal analyses were used to analyze the thermal activity of extracted lignins. Simultaneously, the phenolic acids, aldehydes, and sugar analysis of lignin were determined using high-performance liquid chromatography (HPLC) and high-performance anion-exchange chromatography with pulsed amperometric detection (HPAEC-PAD). To optimize the proper applications of lignin, the physicochemical characteristic of lignin isolated from $\mathrm{CH}$ were compared with several previous works.

\section{EXPERIMENTAL}

\section{Materials}

Coconut husks $(\mathrm{CH})$ were collected in Sungai Petani, Kedah, Malaysia $\left(5^{\circ} 39^{\prime} 08.5^{\prime \prime} \mathrm{N}, 100^{\circ} 31^{\prime} 17.5^{\prime \prime} \mathrm{E}\right)$ in August 2019. The husks were sun-dried for 2 days to remove any excess moisture before being ground into powder using a stainless steel laboratory blender (Waring Commercial, Torrington, CT, USA). Then, the ground CH was sieved into small particles ( 1 to $3 \mathrm{~mm}$ ) and further dried in an oven at $50{ }^{\circ} \mathrm{C}$ for $24 \mathrm{~h}$. The chemical composition $(\% \mathrm{w} / \mathrm{w})$ of the $\mathrm{CH}$ biomass in term of moisture content $(9.26 \pm$ $0.15 \%)$, ash content $(2.50 \pm 0.002 \%)$, extractives content $(9.16 \pm 0.14 \%)$, cellulose content $(27.19 \pm 0.10 \%)$, hemicellulose content $(14.64 \pm 0.70 \%)$, and Klason lignin (37.93 \pm $0.91 \%$ ) was determined based on the National Renewable Energy Laboratory (NSEL) laboratory analytical procedure (LAP) (Sluiter et al. 2005a,b, 2008a,b) and TAPPI T203 cm-09 (2009) standard. The obtained chemical composition in $\mathrm{CH}$ biomass was compared 
with previous studies and is summarized in Table 1. For this study, the chemicals used such as nitrobenzene, $p$-hydroxybenzaldehyde, syringic acid, syringaldehyde, vanillic acid, $p$ hydroxybenzoic acid, vanillin, ferulic acid, and $p$-coumaric acid, were obtained from Sigma-Aldrich (St. Louis, MO, USA). Toluene (grade AR), ethanol (99.7\%), sulfuric acid (98\%), sodium hydroxide (97\%), hydrochloric acid (37\% v/v), glacial acetic acid (99.8\%), dichloromethane, and acetone were purchased from QReC (Rawang, Malaysia). Acetic anhydride ( $\geq 98.5 \%$ ), acetonitrile (HPLC grade), and dimethyl sulfoxide-d6 (d6-DMSO) were obtained from Merck (Darmstadt, Germany). Chloroform (99.8\%) and tetrahydrofuran (HPLC grade 99.99\%) were from Fisher Chemicals (Loughborough, UK). Sodium sulfide $(95 \%)$ was purchased from R\&M Chemical (Essex, UK), as well as pyridine ( $\geq 99.5 \%)$ was purchased from Bendosen (KL, Malaysia). Sodium chlorite $(80 \%)$ pure was obtained from Acros Organics (Morris Plains, NJ, USA). In all experiments, distilled water was used, except that ultrapure water was used for running HPLC and HPAEC-PAD analysis.

Table 1. Comparison of Chemical Composition of Coconut Husk Biomass with Previous Studies (Israel et al. 2011; Lertwattanaruk and Suntijitto 2015; Ram and Mondal 2018)

\begin{tabular}{|c|c|c|c|c|}
\hline Proximate Analysis & \multicolumn{4}{|c|}{ Chemical Composition (\% w/w) } \\
\hline & This Work ${ }^{*}$ & $\begin{array}{c}\text { Lertwattanaruk } \\
\text { and Suntijitto } \\
(2015)\end{array}$ & $\begin{array}{c}\text { Ram and } \\
\text { Mondal (2018) }\end{array}$ & $\begin{array}{c}\text { Israel } \text { et al. } \\
(2011)\end{array}$ \\
\hline Moisture content & $9.26 \pm 0.15$ & NA & 3.40 & 25.50 \\
\hline Ash content & $2.50 \pm 0.01$ & NA & 5.20 & 9.00 \\
\hline Klason lignin & $37.93 \pm 0.91$ & 29.80 & 47.50 & 53.50 \\
\hline Cellulose & $27.19 \pm 0.10$ & 34.90 & 42.30 & 35.90 \\
\hline Hemicellulose & $14.64 \pm 0.70$ & 21.90 & 1.10 & NA \\
\hline Extractives content & $9.16 \pm 0.14$ & NA & 9.10 & NA \\
\hline $\begin{array}{l}\text { * All samples were run in triplicates and the average values as well as the standard deviation } \\
\text { values were reported ( } \mathrm{n}=3 \text { ) }\end{array}$ \\
\hline
\end{tabular}

\section{Extraction of Lignin Using Pulping Process}

A 0.2-L TGYF-A stainless steel small high pressure chemical reactor (Henan Lanphan Industry Co. Ltd., Henan, China) was used when lignin was isolated under an alkaline (kraft and soda) and organosolv pulping process. In the alkaline pulping process, all of the conditions were the same as described in the authors' previous works (Hussin et al. 2013; Aziz et al. 2019) with minor changes. Kraft pulping process was initiated with the addition of active alkali (20\%) and sulfidity (30\%) at a ratio of 1:10 (solid to liquid, $\mathrm{S}: \mathrm{L}$ ). Meanwhile, in the soda pulping process, $30 \%$ of active alkali was used in the same ratio as described above. The maximum temperature, time, and pressure of the two pulping processes were set to $170{ }^{\circ} \mathrm{C}$ (12 to 15 bar) for $3 \mathrm{~h}$. The final products (pulp and black liquor) were collected by separation using vacuum filtration. After that, the concentrated black liquor was acidifed to $\mathrm{pH} 2$ by dropwise addition of $20 \%$ (v/v) of sulfuric acid $\left(\mathrm{H}_{2} \mathrm{SO}_{4}\right)$ to precipitate the kraft and soda lignin. Both precipitated lignins (KL and SL) were centrifuged at $3000 \mathrm{rpm}$ for $15 \mathrm{~min}$ and oven-dried $\left(50{ }^{\circ} \mathrm{C}\right)$ for $24 \mathrm{~h}$. Subsequently, dry kraft and soda lignin were washed with excess water of $\mathrm{pH} 2$ to remove any impurities or the residual of the hemicellulose compound before being dried in the oven $\left(50{ }^{\circ} \mathrm{C}\right)$ for another $24 \mathrm{~h}$. 
In organosolv pulping, the addition of ethanol: water $(65: 35, \mathrm{v} / \mathrm{v})$ and $0.5 \%(\mathrm{w} / \mathrm{w})$ of sulphuric acid as a catalyst was mixed with the same $S: L$ ratio as mentioned in alkaline pulping. As outlined in the method by El Hage et al. (2010), the cooking temperature used was at $190{ }^{\circ} \mathrm{C}$ for $1 \mathrm{~h}$ with continuous stirring. After the process, the fibrous residue was washed three times $(3 \times 50 \mathrm{~mL})$ with $80 \%$ warm ethanol $(\mathrm{v} / \mathrm{v})$, and the concentrated black liquor was secured using vacuum filtration. Then, the concentrated black liquor underwent precipitation with three volumes of water and the lignin was collected using the same centrifuge conditions as described above for alkaline pulping. Finally, the wet solid organosolv lignin (OL) was oven-dried at 50 for $24 \mathrm{~h}$ before being stored in a vial for further analysis (Hussin et al. 2013; Latif et al. 2019). The percentage yields of all collected lignin (KL, SL, and OL) were calculated using Eq. 1 below (Aziz et al. 2019):

$$
\text { Yield }(\%)=\frac{\text { Weight of recovered lignin }(\mathrm{g})}{\text { Weight of } \mathrm{CH}(\mathrm{g})} \times \mathbf{1 0 0}
$$

\section{Klason Lignin (HPAEC-PAD Analyses)}

All the $\mathrm{CH}$ pulp of kraft, soda, and organosolv pulping of extractive-free samples were powder-ground, and the moisture content was measured using a Kern MRS 120-3Mettler Toledo moisture analyzer (Greifensee, Switzerland). Based on the method illustrated by Tahri et al. (2016), approximately $0.175 \mathrm{~g}$ of dried extractive-free pulp samples were measured and put inside the $50-\mathrm{mL}$ centrifuge tubes. Then, $72 \%$ of sulfuric acid $\left(\mathrm{H}_{2} \mathrm{SO}_{4}\right)$ was added to approximately $1.5 \mathrm{~mL}$ in the tubes and the mixture was stirred continuously around $5 \mathrm{~min}$ using a glass rod. After stirring, the tubes were incubated in a $30{ }^{\circ} \mathrm{C}$ water bath for $1 \mathrm{~h}$ before the addition of distilled water $(42 \mathrm{~mL})$ and kept in an autoclave for $1 \mathrm{~h}$. After the tubes were cooled down, the samples were filtered using glass microfibers in a Buchner funnel. The sample residue was washed with distilled water and left to dry in a $105^{\circ} \mathrm{C}$ oven for Klason lignin content. As for the filtrate (soluble fraction), it was transferred into a round bottom flask and diluted to $100 \mathrm{~mL}$ with distilled water for HPAEC-PAD analysis (Dionex ICS-3000, Dionex Corp; Thermo Scientific, Sunnyvale, CA, USA).

From the Klason lignin hydrolysis, the monosaccharide contents of soluble fractions can be separated and analyzed using HPAEC-PAD (ICS-3000 Dionex) equipped with a Dionex CarboPac PA-20 (3 x $150 \mathrm{~mm}$ ) analytical column, as illustrated in Tahri et al. (2016) and Obame et al. (2019). Approximately $20 \mu \mathrm{L}$ of filtered samples were eluted at $35{ }^{\circ} \mathrm{C}$ with a flow rate $(0.4 \mathrm{~mL} / \mathrm{min})$ under the following conditions: $99.2 \%$ pure water and $0.8 \% 250 \mathrm{mM} \mathrm{NaOH}$ (0 to $20 \mathrm{~min}$ ); $75 \%$ pure water, $20 \% 250 \mathrm{mM} \mathrm{NaOH}$, and $5 \% 1$ $\mathrm{M} \mathrm{CH}_{3} \mathrm{COONa} / 20 \mathrm{mM} \mathrm{NaOH}$ (20 to $37 \mathrm{~min}$ ); and $40 \%$ pure water, $20 \% 250 \mathrm{mM} \mathrm{NaOH}$, and $40 \% 1 \mathrm{M} \mathrm{CH}_{3} \mathrm{COONa} / 20 \mathrm{mM} \mathrm{NaOH}$ (37 to $41 \mathrm{~min}$ ). After each elution, there was a wash and a period of equilibration. The external sugar and uronic acid standards were used for calibration with seven points per curve. All the sugar-containing monosaccharides (such as fucose, glucose, xylose, galactose, mannose, rhamnose, arabinose, galacturonic acid, and glucuronic acid) standards were supplied by Sigma-Aldrich (St. Louis, MO, USA).

\section{Lignin Characterization}

Fourier transform infrared analysis

A Thermo-Nicolet IR 2000 (Thermo Scientific; Waltham, MA, USA) FTIR spectrometer coupled with attenuated total reflectance (ATR) head of Perkin Elmer model 
(Waltham, MA, USA) was used to analyze the isolated alkaline and organosolv lignin (KL, SL, and OL) samples under the indirect transmittance mode. The spectra of the vibration bands were recorded across the 600 to $4000 \mathrm{~cm}^{-1}$ region with a resolution of $4 \mathrm{~cm}^{-1}$ and 20 scans per sample.

\section{Acetylation of lignin}

According to Faris et al. (2015), all lignin samples need to undergo an acetylation process to enhance their solubility in organic solvents, especially for NMR spectroscopy and GPC techniques. During the acetylation process, all the hydroxyl $(-\mathrm{OH})$ groups are replaced with acetyl $\left(-\mathrm{COCH}_{3}\right)$ groups. This process was done by dissolving approximately $1.2 \mathrm{~g}$ of lignin in an acetic anhydride/pyridine mixture (1:1), stirring continuously for $24 \mathrm{~h}$ at ambient temperature. After cooling the mixture to $0{ }^{\circ} \mathrm{C}$ with ice cubes, approximately $150 \mathrm{~mL}$ of $1 \%(\mathrm{w} / \mathrm{v})$ hydrochloric acid $(\mathrm{HCl})$ was added dropwise until precipitation developed. Finally, the solid precipitation was collected by vacuum filtration and dried in a $60{ }^{\circ} \mathrm{C}$ oven for $24 \mathrm{~h}$ after being washed with an excess of water until the $\mathrm{pH}$ of filtrate became neutral ( $\mathrm{pH} 6$ to 7 ).

For liquid-state ${ }^{13} \mathrm{C}$ and 2D-HSQC NMR spectroscopy, a volume of $0.5 \mathrm{~mL} \mathrm{d6}$ DMSO solvent was added to the acetylated lignin samples (KL, SL, and OL), and the samples were lightly heated with continuous stirring until completely dissolved. All NMR spectra were acquired using a Bruker Avance $500 \mathrm{MHz}$ NMR spectrometer (Fallanden, Switzerland) with 22000 scans at $50{ }^{\circ} \mathrm{C}$ and interpreted with Bruker TopSpin software (v.3.5, Oxford, MS, USA). Next, the measurement of the average molecular weight $\left(M_{\mathrm{w}}\right)$ and average molecular number $\left(M_{\mathrm{n}}\right)$ were measured using an Agilent GPC model 1200 series analyzer connected to a UV detector (Agilent Technologies, Santa Clara, CA, US). An HPLC grade of mobile phase (tetrahydrofuran, THF) was used with a flow rate of 1.0 $\mathrm{mL}$ min-1 in a Waters 1525 Binary HPLC pump. In brief, approximately $15 \mathrm{mg}$ of acetylated lignin was mixed in $1.5 \mathrm{~mL}$ of THF solvent, and elimination of impurities was done using a $0.40 \mu \mathrm{m}$ filter. Following that, the polydispersity index (PDI) was calculated using the ratio $\left(M_{\mathrm{w}} / M_{\mathrm{n}}\right)$ after about $20 \mu \mathrm{L}$ of solution (filtered) was injected into the GPC instrument.

\section{Thermal analysis}

The thermogravimetric analyses (TGA) of lignin samples (KL, SL, and OL) were studied using a Perkin Elmer TGA 7 analyzer (Waltham, MA, USA). The TGA analysis was performed at a continuous heating rate of $20{ }^{\circ} \mathrm{C} \mathrm{min}^{-1}$ in a nitrogen atmosphere $\left(\mathrm{N}_{2}\right)$ across a temperature range of 30 to $900{ }^{\circ} \mathrm{C}$. Differential scanning calorimetry (DSC) analysis was carried out with a Perkin Elmer Pyris 1 (Waltham, MA, USA) to determine the glass transition temperature $\left(T_{\mathrm{g}}\right)$ of each lignin sample. Each lignin sample was heated at a constant heating rate of $20{ }^{\circ} \mathrm{C} \mathrm{min}{ }^{-1}$ over a temperature range between 30 and $200{ }^{\circ} \mathrm{C}$.

\section{Phenolic acids and aldehydes composition}

A simple nitrobenzene oxidation method was used to determine the S/G ratio of coconut husk lignin by analyzing using high-performance liquid chromatography (HPLC) with minor modifications, as implied by the previous works (Hussin et al. 2013; Latif et al. 2019). Ground-dried lignin (approximately $50 \mathrm{mg}$ ) was placed in a steel autoclave with a mixture of $2 \mathrm{M} \mathrm{NaOH}$ and $5 \mathrm{~mL}$ of nitrobenzene before undergoing oil bath heating at $165^{\circ} \mathrm{C}$ for $3 \mathrm{~h}$. Then, the solution was cooled down in ice water before being transferred to a glass-liquid separation funnel. The extraction was done three times with the addition 
of chloroform in the separation funnel to get rid of the nitrobenzene reduction product. The oxidation mixture (upper layer) was acidified by adding concentrated $\mathrm{HCl}$ solution until reaching a $\mathrm{pH}$ of 2 and 3 before the second extraction was done using chloroform. After the second extraction, the excess chloroform solvent inside the oxidation mixture was removed by an evaporation process using a rotary evaporator heated between 48 and 50 ${ }^{\circ} \mathrm{C}$. The final volume of an organic mixture (as a stock solution) obtained was dissolved with dichloromethane solvent up to $10 \mathrm{~mL}$. A volume of $0.4 \mathrm{~mL}$ of stock solution was pipetted into a 50-mL volumetric flask with subsequent dilution up to the mark with acetonitrile/ultrapure water mixture $(1: 2, \mathrm{v} / \mathrm{v})$. To avoid any impurities and insoluble particles before being injected into the HPLC system, the mixture of stock solution was filtered using a $0.40-\mu \mathrm{m}$ Millipore membrane filter. Without any doubt, the classification of phenolic acids and aldehydes contents in $\mathrm{CH}$ lignin was detected using the Shidmazu HPLC system (Kyoto, Japan) coupled with Thermo Hypersil Gold C18 column (particle size $5 \mu \mathrm{m}$, length $250 \mathrm{~mm}$, inner diameter $64.6 \mathrm{~mm}$ ) by injecting approximately $20 \mu \mathrm{L}$ of the solution. For the mobile phase, a mixture of acetonitrile/ultrapure water $(1: 8, \mathrm{v} / \mathrm{v})$ together with $1 \%(\mathrm{v} / \mathrm{v})$ of acetic acid was used in the HPLC system and operated at a flow rate of $1 \mathrm{~mL} \mathrm{~min}^{-1}$. Each chromatogram of the samples was supervised at $280 \mathrm{~nm}$ using an ultraviolet (UV) detector (Shidmazu HPLC system; Kyoto, Japan).

\section{RESULTS AND DISCUSSION}

\section{Proximate Analysis}

Table 2 summarizes the percentage yields of lignin samples (KL, SL, and OL), as well as the sugar analysis of the resulting hydrolysates with HPAEC-PAD. Kraft and soda lignins produced higher percentage yields $(\%)$ from the alkaline pulping than organosolv lignin. This revealed that alkaline pulping had more severe reaction conditions, which stimulates the delignification process of lignin from $\mathrm{CH}$ biomass (Hussin et al. 2013; Domínguez-Robles et al. 2017). At the same time, organosolv pulping produced a low percentage yield of lignin due to the use of ethanol solvent and low severity reaction conditions, which dissolves the small molecular weight fraction of lignin (Hussin et al. 2013; Latif et al. 2019). According to the literature on the monosaccharide composition of coconut husk $(\mathrm{CH})$, all the pulp in this study after alkaline and organosolv pulping contained a higher proportion of glucose and xylose.

Table 2. Sugar Analysis of Kraft, Soda, and Organosolv Lignin from Coconut Husk (\% w/w on Dry Matter)

\begin{tabular}{|c|c|c|c|}
\hline & $\mathrm{KL}$ & $\mathrm{SL}$ & $\mathrm{OL}$ \\
\hline Yield (\%) & $21.74 \pm 2.04$ & $23.67 \pm 1.82$ & $2.79 \pm 0.30$ \\
\hline Glucose (\%) & $21.83 \pm 1.17$ & $22.19 \pm 5.63$ & $33.26 \pm 3.28$ \\
\hline Xylose (\%) & $64.65 \pm 3.36$ & $65.25 \pm 8.26$ & $58.67 \pm 4.50$ \\
\hline Galactose (\%) & $2.96 \pm 1.68$ & $2.81 \pm 0.41$ & $3.22 \pm 0.15$ \\
\hline Arabinose (\%) & $6.89 \pm 3.92$ & $6.61 \pm 0.90$ & $0.58 \pm 0.05$ \\
\hline Mannose (\%) & $1.32 \pm 0.72$ & $0.96 \pm 0.33$ & $3.34 \pm 0.38$ \\
\hline $\begin{array}{l}* \\
\text { vall samples were run in triplicate and the average values as well as the reported ( } \mathrm{n}=3 \text { ) }\end{array}$ \\
${ }^{*} \mathrm{KL}=$ kraft lignin; $\mathrm{SL}=$ soda lignin; $\mathrm{OL}=$ organosolv lignin \\
\hline
\end{tabular}


All the glucose comes from cellulose, a linear macromolecular polysaccharide that is made up of $\beta$-1,4-glycosidic bonds that connect a long chain of glucose units. Meanwhile, hemicellulose monosaccharide units primarily consist of xylose, arabinose, galactose, mannose, and some low-content saccharides (rhamnose and fructose) (Wang et al. 2017). The cellulosic composition in alkaline substrates pulp (KL and SL) was lower in glucose composition than that of organosolv substrate pulp (OL), resulting in higher removal of lignin because alkaline lignin produced a higher percentage yield of lignin (Sangian and Widjaja 2018).

\section{Structural Characterization of Lignin}

\section{FTIR analysis}

Fourier-transform infrared spectroscopy was used to observe any structural differences in the peak positions of vibrational bands between the three types of lignin compounds (KL, SL, and OL). Figure 2 depicts absorption band functionalities within the expanded region (600 to $1800 \mathrm{~cm}^{-1}$ ) of FTIR spectra in all $\mathrm{CH}$ lignin samples, and the assignment bands are compiled in Table 3. The KL and SL spectra revealed moderately intense $\mathrm{G}$ bands (around 1271 and $1032 \mathrm{~cm}^{-1}$ ) and weakly intense $\mathrm{S}$ bands (around 1331, 1112 , and $826 \mathrm{~cm}^{-1}$ ) while the OL spectra revealed quite strong $\mathrm{G}$ and $\mathrm{S}$ bands. The absorbance signal of $S$ unit bands $\left(1327,1114\right.$, and $\left.826 \mathrm{~cm}^{-1}\right)$ in OL spectra was noticeably higher than that of $\mathrm{G}$ bands in KL and SL, suggesting that the OL sample contained more syringyl content, as reported in the previous literature (Hussin et al. 2013).

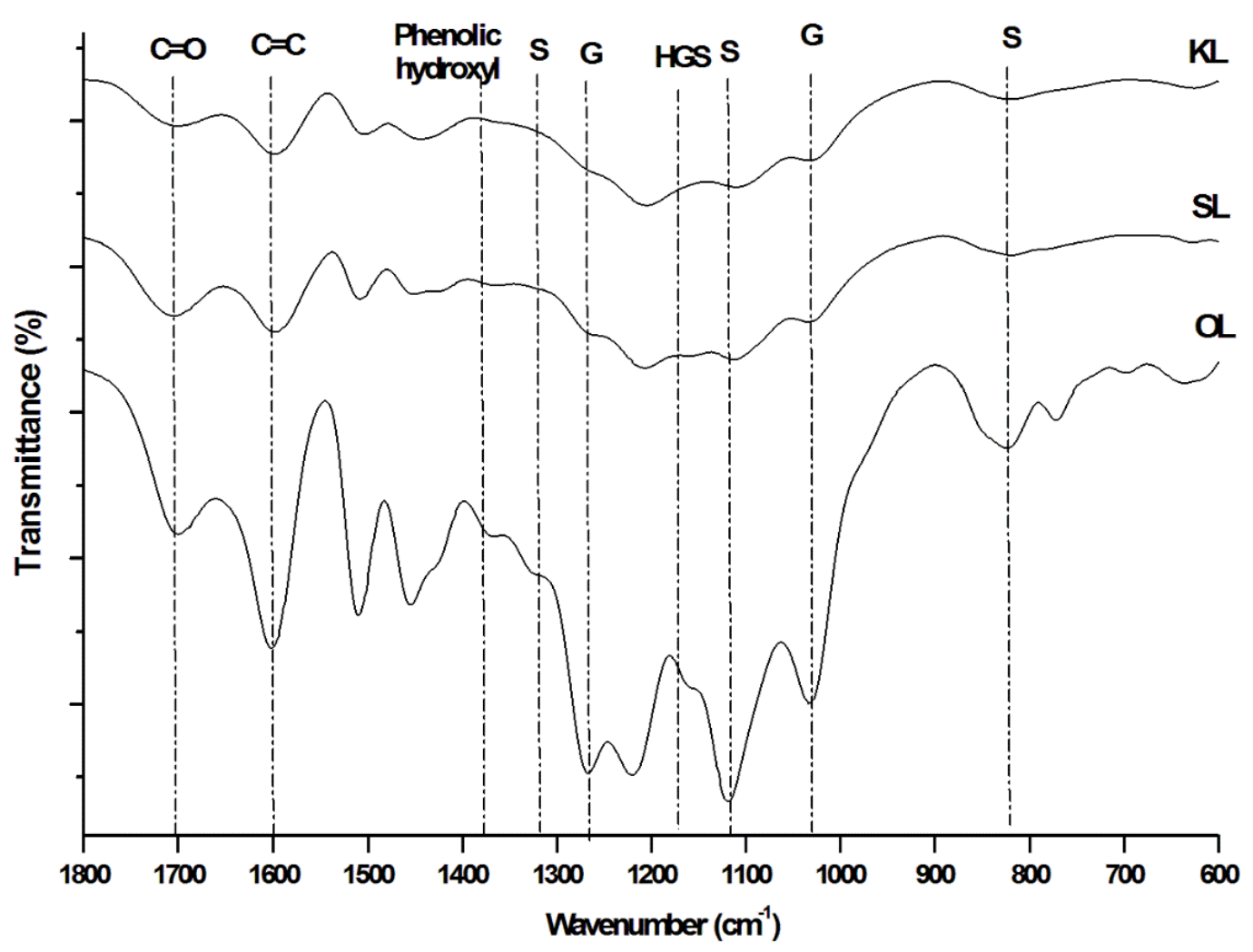

Fig. 2. FTIR spectra of $\mathrm{KL}, \mathrm{SL}$, and $\mathrm{OL}$ isolated from $\mathrm{CH}$ 
Table 3. FTIR Assignment Bands of Coconut Husk Lignin

\begin{tabular}{|c|c|c|c|}
\hline \multirow[t]{2}{*}{ Assignment } & $\mathrm{KL}$ & SL & $\mathrm{OL}$ \\
\hline & \multicolumn{3}{|c|}{ Band Wavenumber $\left(\mathrm{cm}^{-1}\right)$} \\
\hline $\mathrm{C}=\mathrm{O}$ stretching of aldehyde/ketone groups & 1701 & 1702 & 1700 \\
\hline $\mathrm{C}=\mathrm{C}$ stretching vibration in benzene ring & 1600 & 1603 & 1600 \\
\hline $\mathrm{C}=\mathrm{C}$ stretching vibration in benzene ring & 1502 & 1501 & 1503 \\
\hline $\mathrm{C}-\mathrm{H}$ deformation (asymmetric in $-\mathrm{CH}_{3}$ and $-\mathrm{CH}_{2}$ ) & 1444 & 1454 & 1452 \\
\hline $\begin{array}{c}\text { C-C stretching (aromatic skeleton) with } \mathrm{C}-\mathrm{H} \text { in plane } \\
\text { deformation }\end{array}$ & 1422 & 1425 & 1424 \\
\hline $\mathrm{O}-\mathrm{H}$ stretching vibration (phenolic $\mathrm{OH}$ ) & 1361 & 1364 & 1367 \\
\hline C-O stretching (syringyl) & 1331 & 1330 & 1327 \\
\hline $\begin{array}{c}\mathrm{C}-\mathrm{O}(\mathrm{H})+\mathrm{C}-\mathrm{O}(\mathrm{Ar})(\text { phenolic } \mathrm{OH}) \text { and ether in } \\
\text { syringyl and guaiacyl) }\end{array}$ & 1271 & 1269 & 1269 \\
\hline $\mathrm{Ar}-\mathrm{CH}$ in plane deformation (syringyl) & 1111 & 1112 & 1114 \\
\hline $\begin{array}{c}\mathrm{C}-\mathrm{O}(\mathrm{H})+\mathrm{C}-\mathrm{O}(\mathrm{C}) \begin{array}{c}\text { (first-order aliphatic } \mathrm{OH} \text { and } \\
\text { ether) }\end{array} \\
\end{array}$ & 1032 & 1030 & 1034 \\
\hline $\mathrm{C}-\mathrm{H}$ out of plane (aromatic) & 915 & 915 & 916 \\
\hline $\mathrm{C}-\mathrm{H}$ out of plane & 826 & 824 & 826 \\
\hline
\end{tabular}

The use of mixture solvent (ethanol-water) in organosolv pulping leads to the presence of free acetic acid from hemicelluloses, which contributes to lignin dissolution. As a result, it stimulates acid hydrolysis of the lignin structure, resulting in more intense peaks of the phenolic groups $\left(1367 \mathrm{~cm}^{-1}\right)$ and carbonyl groups $\left(1700 \mathrm{~cm}^{-1}\right)$ than alkaline pulping (Latif et al. 2019). In comparison, KL and SL samples had remarkably higher G bands intensities than OL, which was primarily because of the demethoxylation during the alkaline pulping process. It has been stated that demethoxylation reactions occur under severe reaction conditions during the alkaline pulping process, resulting in more stable Gtype structures from S-type groups within the lignin molecules (Hussin et al. 2013; Aziz et al. 2019). According to Aziz et al. (2019), the presence of more G-type units in the lignin structure demonstrated that lignin had a better potential as an active site for polymerization. Furthermore, the typical absorption signal of HGS units for all lignin isolated from $\mathrm{CH}$ is comparable to wood lignin rather than occurring plant lignin due to a lack of hydroxyl phenyl propane $(\mathrm{H})$ band in the spectra around $1160 \mathrm{~cm}^{-1}$ (Hussin et al. 2018). Hereby, it was confirmed that all the $\mathrm{CH}$ lignin structures produced are primarily made up of S-type and G-type units.

\section{NMR spectral analysis}

The structural properties of all acetylated $\mathrm{CH}$ lignin were further characterized via NMR techniques. All the spectra were interpreted and compared with the other previous research as a reference on acetylated lignin (Sa'don et al. 2017a,b; Aziz et al. 2019; Latif et al. 2019). As shown in Fig. 3 and summarized in Table 4, the ${ }^{13} \mathrm{C}$ NMR spectra of all acetylated lignin were qualitatively and quantitatively measured and placed into different categories of hydroxyl groups $(-\mathrm{OH})$ and their derivatives. As the reference, the integral of the 162 to $102 \mathrm{ppm}$ region was used, with six aromatic carbons and 0.12 vinylic carbons assumed. The integral value was divided by 6.12 , which corresponded to one aromatic ring (Hussin et al. 2013). Within the integral region between 172 and $165 \mathrm{ppm}$ chemical shift, the number of hydroxyl (-OH) groups in acetylated lignin samples were calculated. In all acetylated lignin spectra, the presence of guaicyl, syringyl, and p-hydroxyphenyl units was associated with the aromatic region at 100 to $160 \mathrm{ppm}$ (Fig. 3). According to the previous studies, the signals of S units were revealed around 104, 139, and 154 ppm (carbon 
positions $\mathrm{C} 2 / \mathrm{C} 6, \mathrm{C} 4$, and $\mathrm{C} 3 / \mathrm{C} 5)$, while $\mathrm{G}$ units signals were found at 113, 119, 135, and 146 ppm (carbon positions C2, C6, etherified C1, and non-etherified C3). The signal of 127 ppm was attributed to the $\mathrm{H}$ units in both alkaline and organosolv lignin samples. Furthermore, the carbon in carbonyl and carboxyl groups produced by the aliphatic esters and aliphatic carboxyls in lignin structures resulted in $172 \mathrm{ppm}$ and $170 \mathrm{ppm}$ showing a strong and moderate signal, respectively (El Hage et al. 2009; Hussin et al. 2013; Aziz et al. 2019). Moreover, the higher $\mathrm{G}$ unit signals in all acetylated lignin samples implied that $\mathrm{CH}$ lignin consists of a higher content of guaiacyl (G) units compared to the syringyl (S) units, as indicated by FTIR analysis and reported by Aziz et al. (2019).

Based on the integration of acetylated lignin samples, Fig. 3 and Table 4 show the amount of primary aliphatic (172.0 to $169.6 \mathrm{ppm}$ ), secondary aliphatic (169.6 to 168.6 ppm), phenol hydroxyl groups (168.6 to $165.0 \mathrm{ppm}$ ), and methoxy groups (58 to $54 \mathrm{ppm}$ ). The methoxy groups $\left(-\mathrm{OCH}_{3}\right)$ in $\mathrm{G}$ and $\mathrm{S}$ units in the lignin structures were assigned to the sharp peak observed at signal $57 \mathrm{ppm}$. It was detected that OL had a higher quantity of primary aliphatic - $\mathrm{OH}(0.49 / \mathrm{Ar})$ than $\mathrm{KL}(0.13 / \mathrm{Ar})$ and SL (0.16/Ar). For the amount of secondary aliphatic - OH, the KL (0.28/Ar) and SL (0.27/Ar) were nearly unchanged, but the OL (0.18/Ar) was remarkably lower. According to the previous study, the value of primary aliphatic-OH groups driven from integrals at 172 to $165 \mathrm{ppm}$ and 65 to $58 \mathrm{ppm}$ (0.97/Ar) had a good correlation for OL, indicating a higher amount of primary aliphatic$\mathrm{OH}(0.49 / \mathrm{Ar}$ ) functional groups in lignin structures (Hussin et al. 2013).

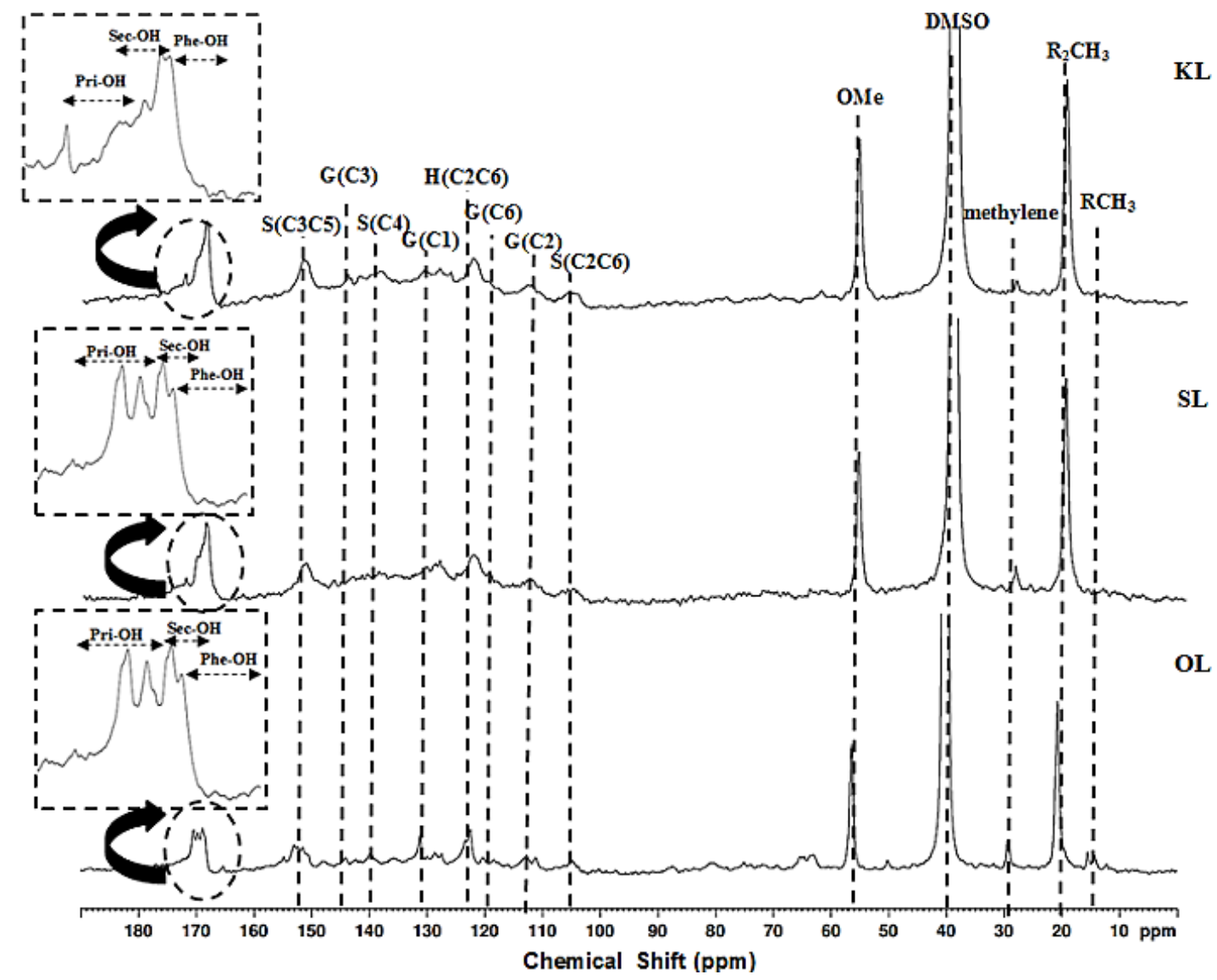

Fig. 3. ${ }^{13} \mathrm{C}$ NMR spectrum of acetylated coconut husk $\mathrm{KL}, \mathrm{SL}$, and $\mathrm{OL}$ 
Moreover, the amount of phenolic-OH in SL (0.25/Ar) and KL (0.19/Ar) were higher than in OL (0.15/Ar) because during alkaline pulping, the $\mathrm{CH}$ biomass undergoes a significant cleavage of aryl-ether bonds, resulting in a greater amount of phenolic hydroxyl groups. According to Aziz et al. (2019), in a study on the utilization of alkaline lignin from coconut husk biomass, the phenolic-OH content of SL (0.82/Ar) was also higher than that of KL (0.76/Ar), as shown in Table 4. As a result, it has been demonstrated that isolation of lignin from $\mathrm{CH}$ biomass using soda pulping produced lignin structures with a high amount of phenolic content. Furthermore, an increased amount of phenolic-OH content in the lignin structure allows for the activation of free ring position during the polymerization reaction, making it more reactive especially during the resinification process of phenolic resins (Hussin et al. 2018; Aziz et al. 2019).

Table 4. Comparison of Signal Assignment for ${ }^{13} \mathrm{C}$ NMR Spectroscopy of Acetylated Coconut Husk of KL, SL, and OL with the Previous Study (Aziz et al. 2019)

\begin{tabular}{|c|c|c|c|c|c|c|}
\hline \multirow{2}{*}{$\begin{array}{l}\text { Range } \\
\text { (ppm) }\end{array}$} & \multirow[t]{2}{*}{ Assignment } & \multicolumn{5}{|c|}{ Amount (per Ar) } \\
\hline & & $\overline{K L}$ & SL & $\mathrm{OL}$ & $\mathrm{KL}^{*}$ & $\mathrm{SL}^{*}$ \\
\hline $\begin{array}{l}172 \text { to } \\
169.6\end{array}$ & Primary aliphatic $-\mathrm{OH}$ & 0.13 & 0.16 & 0.49 & 0.16 & 0.22 \\
\hline $\begin{array}{c}169.6 \text { to } \\
168.6\end{array}$ & $\begin{array}{c}\text { Secondary aliphatic - } \\
\mathrm{OH}\end{array}$ & 0.28 & 0.27 & 0.18 & 0.39 & 0.35 \\
\hline $\begin{array}{c}168.6 \text { to } \\
165\end{array}$ & $\begin{array}{c}\text { Phenolic-OH, } \\
\text { conjugated - COOR }\end{array}$ & 0.19 & 0.25 & 0.15 & 0.76 & 0.82 \\
\hline 155 to 142 & Aromatic $\mathrm{C}-\mathrm{O}$ & 1.78 & 1.94 & 1.96 & & \\
\hline 142 to 124 & Aromatic $\mathrm{C}-\mathrm{C}$ & 2.21 & 2.68 & 2.02 & & \\
\hline 124 to 102 & Aromatic $\mathrm{C}-\mathrm{H}$ & 2.12 & 2.66 & 2.13 & & \\
\hline 89 to 78 & $\begin{array}{c}\mathrm{C} \beta \text { in } \beta-\mathrm{O}-4, \mathrm{C} \alpha \text { in } \beta 5 \\
\text { and } \beta \beta\end{array}$ & & & 1.63 & & \\
\hline 73 to 71 & $\mathrm{C} \alpha$ in $\beta-\mathrm{O}-4$ & & & 0.19 & & \\
\hline 64 to 61 & $C \gamma$ & & & 0.44 & & \\
\hline 58 to 54 & $\mathrm{OMe}, \mathrm{C} 1$, and $\mathrm{C} \beta$ & 0.39 & 0.51 & 0.38 & & \\
\hline 90 to 58 & Alk-O & & & 2.33 & & \\
\hline 65 to 58 & $\mathrm{OH}_{\text {prim }}$ & & & 0.97 & 0.16 & 1.30 \\
\hline 31 to 29 & $\alpha, \beta$ Methylene groups & & & 0.48 & & \\
\hline 21 & $\mathrm{CH}_{3}$ in acetyl group & & & 0.43 & & \\
\hline 19 & $\mathrm{OCH}_{2} \mathrm{CH}_{3}$ & & & 0.32 & & \\
\hline 15 & $\begin{array}{l}\gamma \text { Methyl in n-propyl } \\
\text { side chain }\end{array}$ & & & 0.26 & & \\
\hline
\end{tabular}

The 2D-HSQC NMR spectrum was used to obtain details on the structural composition of all lignin samples. In the aromatic region of the HSQC spectrum, the main signals $\left(\delta \mathrm{C} / \delta_{\mathrm{H}} 160\right.$ to $100 / 6.0$ to $\left.8.0 \mathrm{ppm}\right)$ are depicted in Fig. 4 (a, b, and c). According to the previous studies (Hussin et al. 2014; Sa'don et al. 2017a; Latif et al. 2019), the correlation at $\delta \mathrm{c} / \delta_{\mathrm{H}}(104.8 / 6.73 \mathrm{ppm})$ was assigned to $\mathrm{C}_{2} / \mathrm{C}_{6}$ position of syringyl (S) units, while the correlation for guaiacyl $(\mathrm{G})$ units was assigned at $\delta \mathrm{C} / \delta_{\mathrm{H}} 107.7 / 6.9$ to $7.2 \mathrm{ppm}$ $\left(\mathrm{C}_{2} / \mathrm{H}_{2}\right)$ and $\delta_{\mathrm{C}} / \delta_{\mathrm{H}} 115.4 / 6.8$ to $6.9 \mathrm{ppm}\left(\mathrm{C}_{5} / \mathrm{H}_{5}\right)$. Furthermore, the signal for $\mathrm{p}-$ 
hydroxyphenyl $(\mathrm{H})$ units was assigned at a correlation of $\delta \mathrm{C} / \delta_{\mathrm{H}}(130.5 / 7.25 \mathrm{ppm})$. This information was in strong agreement with the FTIR and ${ }^{13} \mathrm{C}$ NMR results, which confirmed kraft, soda, and organosolv lignin as natural HGS units lignin. The p-coumarate (pCE 2/6) correlations were encountered at the $\delta \mathrm{c} / \delta_{\mathrm{H}}(126.8 / 7.4$ to $7.6 \mathrm{ppm})$ region.
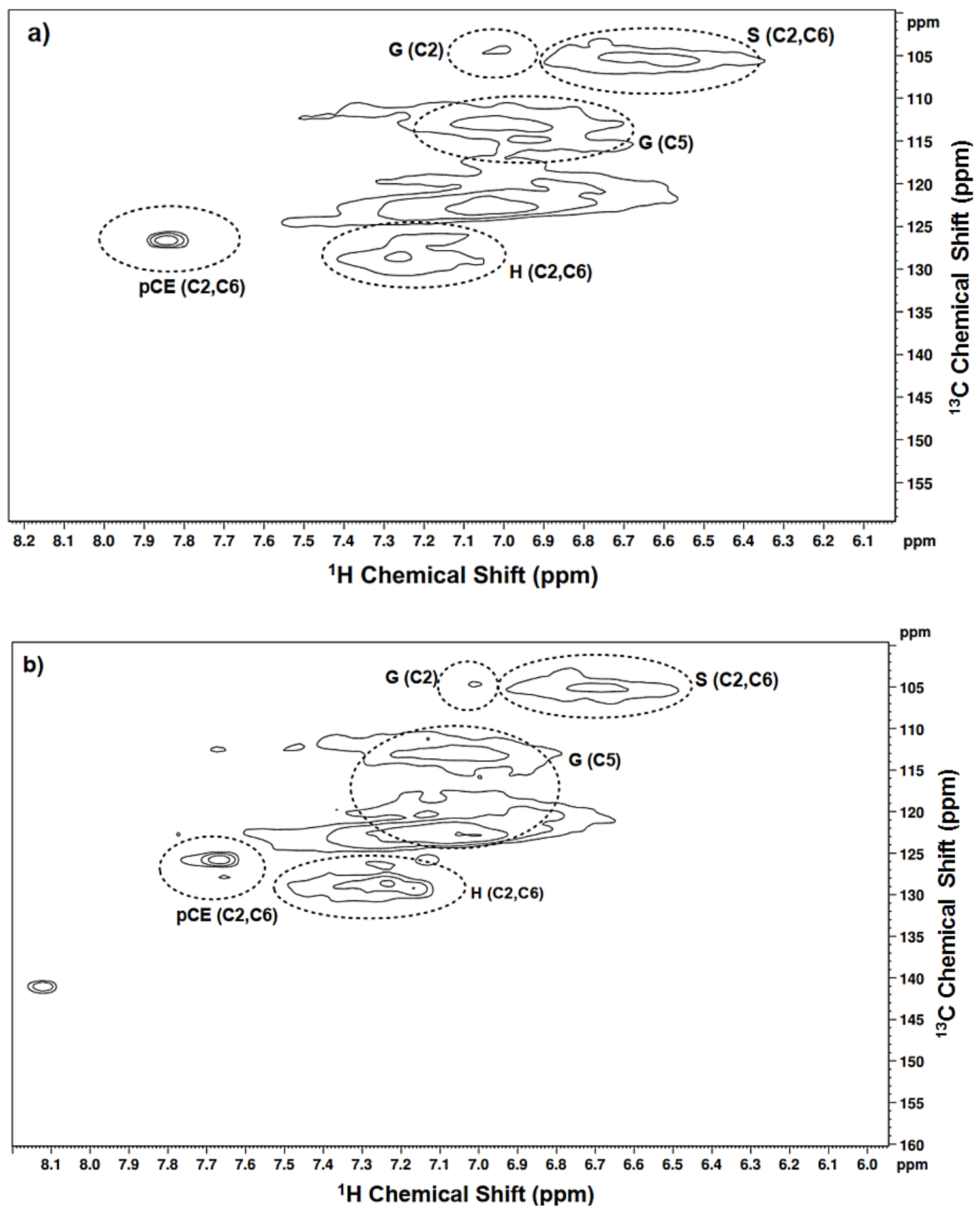


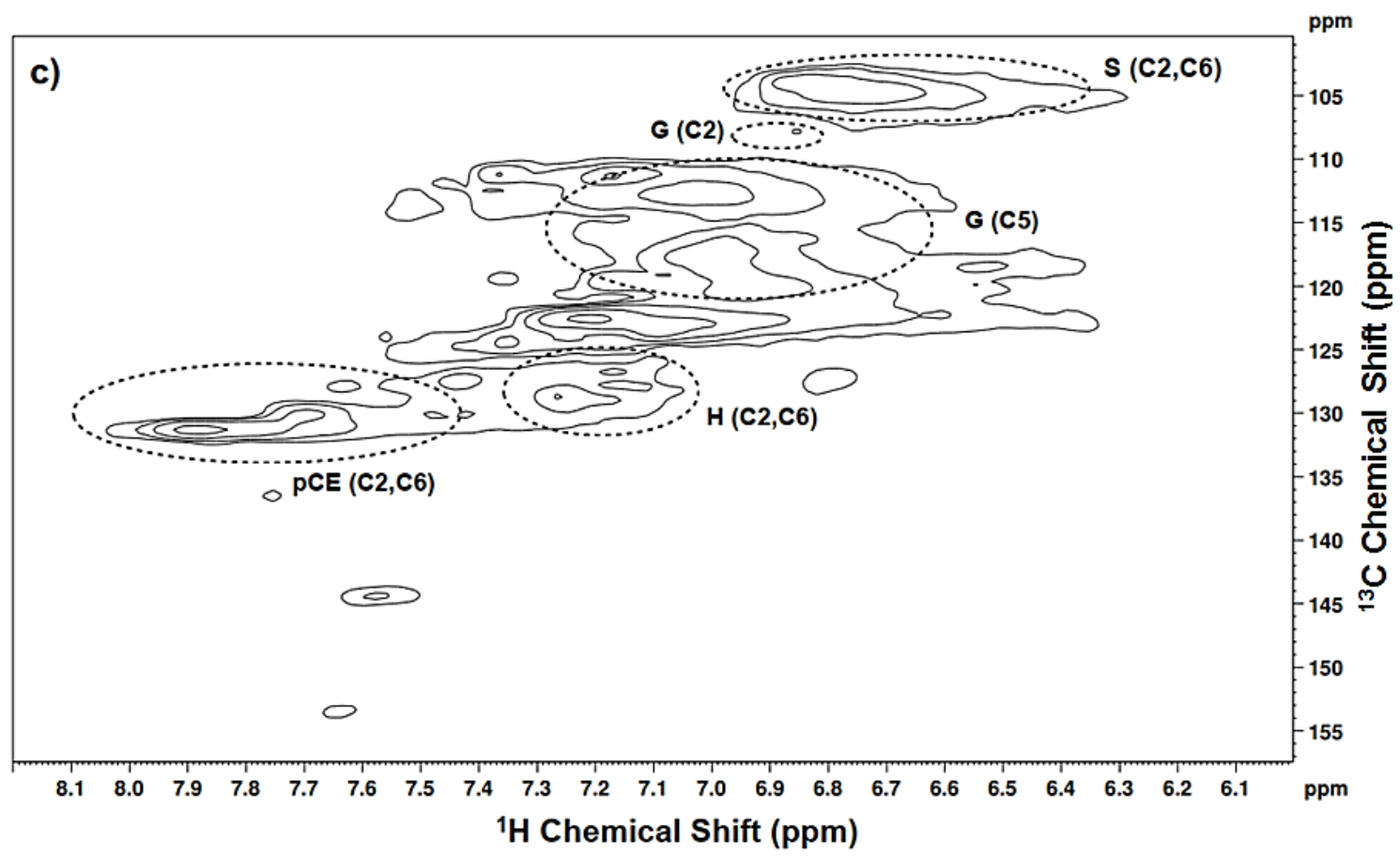

Fig. 4. 2D-HSQC NMR spectrum of acetylated coconut husk a) $K L$, b) $S L$, and c) $O L$

\section{GPC analysis}

Gel permeation chromatography was used to investigate the changes in molecules size and the distribution of alkaline and organosolv acetylated lignin samples. Table 5 shows the polydispersity value (PD) of the lignin fraction, which was calculated by dividing the value of average molecular weight $\left(M_{\mathrm{w}}\right)$ by the average molecular number $\left(M_{\mathrm{n}}\right)$. Based on Table 5, the SL sample had the highest $M_{\mathrm{w}}\left(M_{\mathrm{w} \mathrm{SL}}: 959 \mathrm{~g} \mathrm{~mol}^{-1}>M_{\mathrm{w} \mathrm{KL}}\right.$ : $769 \mathrm{~g} \mathrm{~mol}^{-1}>M_{\mathrm{w}} \mathrm{OL}: 606 \mathrm{~g} \mathrm{~mol}^{-1}$ ) and polydispersity values (PD) (PD SL: $2.44>$ PD KL: $2.32>$ PD OL: 1.37) when compared to KL and OL samples. This observation could be attributed to the different lignin compositions produced by the various pulping processes. According to the previous studies, the molecular weight of lignin may be related to some amounts of $\mathrm{C}-\mathrm{C}$ bonds between phenylpropanoic units (involved in the $\mathrm{C} 5$ aromatic ring), even though $\beta-\mathrm{O}-4$ linkages are the most common linkages in all types of lignin. It was reported that when guaiacyl-type $(G)$ units were compared to syringyl-type $(S)$ units, the G-type units were more adequate to form these $\mathrm{C}-\mathrm{C}$ bonds because $\mathrm{S}$-type units contained both substitution of $\mathrm{C} 3$ and $\mathrm{C} 5$ positions of methoxy groups. This explains why during the pulping process, this kind of $\mathrm{C}-\mathrm{C}$ bond does not cleave due to its high stability. Thus, lignin with more guaiacyl-type $(\mathrm{G})$ units was anticipated to result in an increased amount of molecular weight than lignin with syringyl-type (S) units (Hussin et al. 2013; Aziz et al. 2019). The difference in $M_{\mathrm{w}}$ values between KL and SL could be associated with the repolymerization reaction that occurs during the alkaline pulping method. During the kraft pulping method, the hydroxide and hydrosulfide anions react with lignin molecules, resulting in smaller water/alkali soluble-fragments of the polymer. Because of the production of a smaller molecular weight of KL, this fragmentation was extended through the cleavage of $\alpha$-aryl ether and $\beta$-aryl ether bonds, which is the primary process in alkaline medium (Ibrahim et al. 2011). The results obtained for alkaline lignin (KL and SL) were further reviewed with the previous research (in terms of the same source of raw material 
and pulping process). The $M_{\mathrm{w}}$ value of SL $\left(M_{\mathrm{w} \mathrm{SL}}: 2076 \mathrm{~g} \mathrm{~mol}^{-1}\right)$, and $\mathrm{KL}\left(M_{\mathrm{w} \mathrm{KL}}: 1639 \mathrm{~g}\right.$

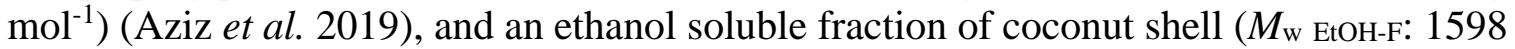
$\mathrm{g} \mathrm{mol}^{-1}$ ) (Avelino et al. 2019) were higher than $M_{\mathrm{w}}$ values obtained in this study. As previously reported, the OL would result in low $M_{\mathrm{w}}$ value with smaller fragments due to the breaking of carbohydrate-lignin $\alpha-\mathrm{O}-4$ bonds and $\beta-\mathrm{O}-4$ bonds to a limited extent during the organosolv pulping process. Because OL has a lower polydispersity (PD) value than KL and SL, it is predicted that OL will have a higher solubility in some organic solvents than other lignin derivatives (Hussin et al. 2013; Sa'don et al. 2017a, 2017b; Latif et al. 2019). Many studies focused on the preparation of phenolic resins with a higher molecular weight of lignin samples (KL and SL) due to the activation of more free ring positions in G-type units (Hussin et al. 2018; Aziz et al. 2019; Hussin et al. 2019).

Table 5. Comparison of GPC Analysis of All Acetylated Alkaline and Organosolv Lignin with the Previous Studies (Avelino et al. 2019; Aziz et al. 2019)

\begin{tabular}{|c|c|c|c|}
\hline Lignin & $M_{\mathrm{w}}\left(\mathrm{g} \mathrm{mol}^{-1}\right)$ & $M_{\mathrm{n}}\left(\mathrm{g} \mathrm{mol}^{-1}\right)$ & $\mathrm{PD}\left(M_{\mathrm{w}} / M_{\mathrm{n}}\right)$ \\
\hline $\mathrm{KL}$ & 769 & 331 & 2.32 \\
\hline $\mathrm{SL}$ & 959 & 393 & 2.44 \\
\hline $\mathrm{OL}$ & 606 & 441 & 1.37 \\
\hline $\mathrm{SL}^{*}$ & 2076 & 513 & 4.05 \\
\hline $\mathrm{KL}^{*}$ & 1639 & 488 & 3.36 \\
\hline $\mathrm{EtOH}-\mathrm{F}^{*}$ & 1598 & 807 & 1.98 \\
\hline & ${ }^{*}$ This is in reference to results obtained from Aziz et al. (2019) and Avelino et al. (2019) \\
\hline
\end{tabular}

\section{Thermal behaviour analysis}

Lignin is now extensively used in a variety of applications, especially in high temperature environments; thus, lignin's thermal decomposition has been studied (Watkins et al. 2015; Aziz et al. 2019; Latif et al. 2019). The thermal behaviour of alkaline lignin (KL and SL) and OL were studied using TGA and DSC. The thermogravimetric (TG) and derivative thermogravimetric (DTG) thermograms of all lignin samples are shown in Fig. $5 \mathrm{a}, 5 \mathrm{~b}$, and summarized in Table 6 . The TG thermogram presents the weight loss of lignin as a function of thermal degradation temperature, while the DTG thermogram shows the corresponding rate of weight loss relative to temperature. All lignin thermograms were referred to and compared to the previous studies published in peer-reviewed journals (Ibrahim et al. 2011; Hussin et al. 2013; Watkins et al. 2015; Latif et al. 2019). The initial degradation step at around 30 to $180{ }^{\circ} \mathrm{C}$ was mainly caused by the evaporation of water absorbed, loss of carbon monoxide $(\mathrm{CO})$, carbon dioxide $\left(\mathrm{CO}_{2}\right)$, and other volatile components caused by the lignin propanoid side-chain cleavage (Watkins et al. 2015; Latif et al. 2019). Simultaneously, the second degradation step (around 250 to $300{ }^{\circ} \mathrm{C}$ ) in the lignin structures was explained based on the weight loss of hemicelluloses. Previous studies have shown that hemicellulose exists as a by-product during lignin precipitation, and degradation occurred at a temperature range from 200 to $300{ }^{\circ} \mathrm{C}$ (Ibrahim et al. 2011; Hussin et al. 2013; Aziz et al. 2019). In Fig. 5b, the maximum rates of weight loss $\left(\mathrm{DTG}_{\max }\right)$ of all lignin samples were noticed at $383{ }^{\circ} \mathrm{C}(\mathrm{KL}), 391{ }^{\circ} \mathrm{C}(\mathrm{SL})$, and $352{ }^{\circ} \mathrm{C}(\mathrm{OL})$. For comparison, in some previous studies on the isolation of lignin from coconut husk/fibre, a similar aspect was detected where KL and SL respectively recorded a DTG max $_{\text {}}$ of 391 and $388{ }^{\circ} \mathrm{C}$ (Aziz et al. 2019) while organosolv lignins had a DTG $\max$ of approximately $350{ }^{\circ} \mathrm{C}$ (Watkins et al. 2015). 

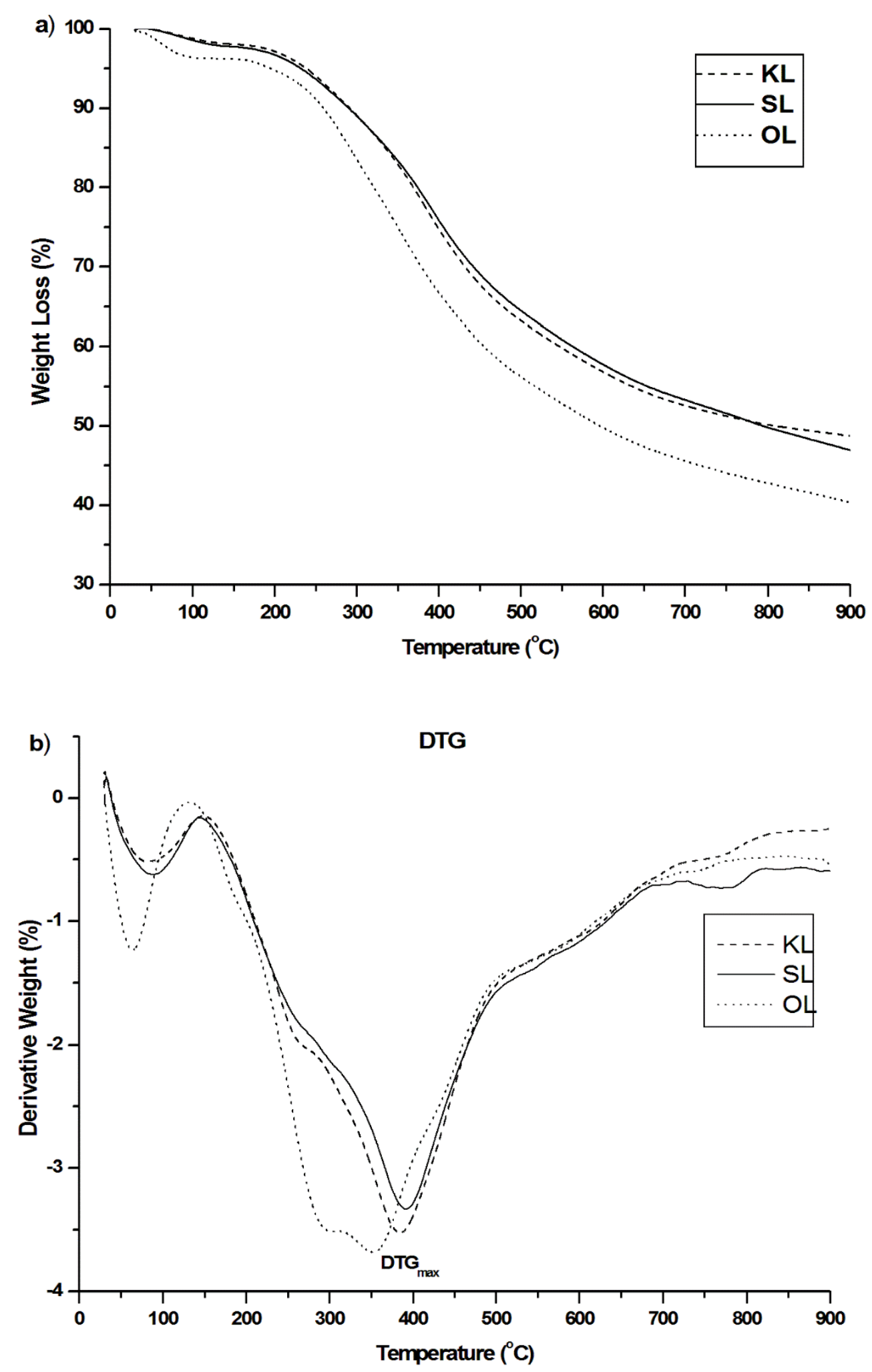

Fig. 5. (a) TGA and (b) DTG thermograms of $\mathrm{KL}, \mathrm{SL}$, and $\mathrm{OL}$ isolated from $\mathrm{CH}$ 
Table 6. TGA-DTG Results of $\mathrm{KL}, \mathrm{SL}$ and $\mathrm{OL}$ isolated from $\mathrm{CH}$

\begin{tabular}{|c|c|c|c|}
\hline $\mathrm{CH}$ lignin & $\mathrm{KL}$ & $\mathrm{SL}$ & $\mathrm{OL}$ \\
\hline $\begin{array}{c}\text { Initial weight loss temperature, } \\
T_{-5 \%}\left({ }^{\circ} \mathrm{C}\right)\end{array}$ & 263 & 262 & 229 \\
\hline $\begin{array}{c}\text { Peak temperature of weight } \\
\left.\text { loss, DTG } \text { max }^{\circ} \mathrm{C}\right)\end{array}$ & 383 & 391 & 352 \\
\hline Residual weight at $900^{\circ} \mathrm{C}(\%)$ & 48.58 & 46.49 & 40.02 \\
\hline
\end{tabular}

Therefore, it was concluded that the major degradation step for a complex lignin structure occurred around 300 to $400{ }^{\circ} \mathrm{C}$. The thermal degradation of volatile products derived from the complex lignin structures, such as the inter-unit linkages fragmentation between phenolics hydroxyl, carbonyl groups (aldehyde acids), and benzylic hydroxyl will release the monomeric phenols in the form of vapor phase (Ibrahim et al. 2011; Watkins et al. 2015). A broad DTGmax curve was observed in the OL thermogram, which could be related to the fact that under low-temperature lignin could undergo degradation, implying that the structure of lignin consisted of smaller fragments, indicating an additional amount of $\beta$-O-4 linkages present with fewer $\mathrm{C}-\mathrm{C}$ interlinked bonds (Hussin et al. 2013). At temperatures above $400{ }^{\circ} \mathrm{C}$, all lignin samples showed a continuous weight loss until up to $900{ }^{\circ} \mathrm{C}$, which could be relevant to the degradation or condensation reactions of aromatic moieties (Hussin et al. 2013; Latif et al. 2019). At the same time, around $900{ }^{\circ} \mathrm{C}$ in Fig. 5 a, approximately $48.58 \%(\mathrm{KL}), 46.49 \%(\mathrm{SL})$, and $40.02 \%$ (OL) of non-volatile residues remained intact and were not completely burned. Hence, it was suggested that a higher percentage of residues revealed that the char products in lignin samples are thermally stable at high temperatures, which can be attributed to the formation of a highly condensed aromatic structure with a high degree of branching (Hussin et al. 2013; Obame et al. 2019).

Differential scanning calorimetry analysis is an effective thermal method for determining the glass transition temperature $\left(T_{\mathrm{g}}\right)$ of polymers concerning their industrial applications and processing. The $T_{\mathrm{g}}$ value is an important temperature for determining the significant properties of amorphous polymers (lignin), which undergo a transition from a glassy-to-rubbery state at a specific temperature (Ibrahim et al. 2011; Hussin et al. 2018). It was discovered that $\mathrm{SL}$ had the highest $T_{\mathrm{g}}$ value $\left(103.69^{\circ} \mathrm{C}\right)$ when compared to $\mathrm{KL}\left(T_{\mathrm{g}}\right.$ : $\left.91.31{ }^{\circ} \mathrm{C}\right)$ and $\mathrm{OL}\left(\mathrm{T}_{\mathrm{g}}: 70.89{ }^{\circ} \mathrm{C}\right)$, which could be attributed to the influence of the molecular weight and free volume present in the lignin samples (Hussin et al. 2013). In theory, free volume refers to the space of a solid or liquid sample that is not occupied by polymer molecules, whereas activation energies can be used to describe $T_{\mathrm{g}}$ (Ibrahim et al. 2011). The $T_{\mathrm{g}}$ value will appear only after the main chains have accumulated enough energy to rotate their segments. The lignin chains will vibrate as usual with the addition of energy, but as extra energy is added, rotation of the chain segment occurred and resulted in the presence of free space. With the increasing $T_{\mathrm{g}}$ value, lignin with higher molecular weight produced fewer chains ends and resulted in lower mobility, thus demanding more energy for rotation to occur (Ibrahim et al. 2011; Hussin et al. 2013; Latif et al. 2019). Therefore, the higher molecular weight of alkaline lignin (SL and KL) observed in GPC analysis indicated that alkaline samples had a few chain ends, which increased the energy required to rotate the chains due to the more free space created compared to OL. These findings also correlated with previous studies: kraft lignin, $\mathrm{KL}\left(T_{\mathrm{g}}: 66.73{ }^{\circ} \mathrm{C}\right)$, soda lignin, SL $\left(T_{\mathrm{g}}: 75.78{ }^{\circ} \mathrm{C}\right)$ (Aziz et al. 2019), and organosolv lignin, EtOH-F $\left(T_{\mathrm{g}}: 133.00{ }^{\circ} \mathrm{C}\right.$ ) (Avelino et al. 2019), and it demonstrated that the alkaline lignin (SL and KL) in this study had higher $T_{\mathrm{g}}$ value but lower $T_{\mathrm{g}}$ value of $\mathrm{OL}$ in terms of using coconut husk wastes. 
According to the thermal analysis data obtained in this study following the GPC analysis, lignin produced by the alkaline pulping process had a higher molecular weight with larger fragments than the organosolv pulping process, resulting in an increase of the $T_{\mathrm{g}}$ value.

\section{Aldehydes and phenolic acids chemical composition}

Alkaline nitrobenzene oxidation is a simple and widely used method to elucidate the constitutive structural compositions of the lignin samples. During the oxidation process in Fig. 6, the main components of lignin units (H, G, and S) were oxidized into aromatic aldehydes and ketones (syringic acid (SA), syringaldehyde (S), vanillin (V), vanillic acid (VA), $p$-hydroxybenzaldehyde (PHB), and $p$-hydroxybenzoic acid (PHBA) by forming a methane semiquinone intermediate (Huang et al. 2019; Jiang et al. 2019). In contrast, the presence of common HGS units in each sample showed that $\mathrm{CH}$ lignin is the HGS type. Based on our previous studies on oil palm fronds (OPF) lignin (Hussin et al. 2013; Latif et al. 2019), Table 7 summarizes the analysis of phenolic acids and aldehydes produced by the alkaline nitrobenzene oxidation of $\mathrm{CH}$ lignin by a different pulping process. The molar ratio values of $G, S$, and $H$ were calculated at a molar ratio of $G: S: H$ (49:38:10) in SL, 39:36:22 in KL, and 33:34:20 in OL, respectively. The molar ratio between G:S units of alkaline samples (KL and SL) revealed that guaiacyl $(G)$ units had a higher value than $S$ units but in the OL sample, the higher value of $\mathrm{S}$ units was obtained. Similar studies have found that non-condensed $S$ units can easily be degraded using the organosolv pulping method when compared to lignin isolated from alkaline pulping (Hussin et al. 2013; Latif et al. 2019). The higher value of $\mathrm{G}$ units present in alkaline lignin samples (KL and SL) was supported in FTIR and GPC analysis, suggesting that $\mathrm{CH}$ lignin could be a valuable active site for cross-linking, especially during the resinification process in the wood adhesives industry (Hussin et al. 2018; Aziz et al. 2019). Therefore, it was discovered that lignin isolated from coconut husk via different pulping methods yielded a high amount of non-condensed $\mathrm{G}$ and $\mathrm{S}$ units, which will be useful in a variety of applications.

Table 7. Yield (\% Dry Sample, w/w) of Phenolic Acids and Aldehydes from Alkaline Nitrobenzene Oxidation of $\mathrm{CH}$ Lignin

\begin{tabular}{|c|c|c|c|c|}
\hline \multirow{2}{*}{ Component } & \multirow{2}{*}{ Rt $(\mathrm{min})$} & \multicolumn{3}{|c|}{ \% Weight (Dry Basis) } \\
\cline { 3 - 5 } & & $\mathrm{KL}$ & $\mathrm{SL}$ & $\mathrm{OL}$ \\
\hline p-Hydroxybenzoic acid (PHBA) & $\sim 8.01$ & 1.07 & 0.58 & 0.69 \\
\hline Vanilic acid (VA) & $\sim 9.52$ & 0.59 & 1.34 & 0.19 \\
\hline Syringic acid (SA) & $\sim 10.47$ & 0.70 & 1.23 & 0.31 \\
\hline p-Hydroxybenzaldehyde (PHB) & $\sim 10.96$ & 0.11 & 0.25 & 0.16 \\
\hline Vanillin (V) & $\sim 13.96$ & 1.49 & 2.79 & 1.19 \\
\hline Syringaldehyde (S) & $\sim 16.80$ & 1.21 & 1.89 & 1.12 \\
\hline Ferulic acid (FA) & $\sim 18.00$ & 0.18 & 0.23 & 0.56 \\
\hline Molar ratio (G:S:H) & & $39: 36: 22$ & $49: 38: 10$ & $33: 34: 20$ \\
\hline S/G Ratio & & 0.92 & 0.78 & 1.03 \\
\hline
\end{tabular}


a)<smiles>COc1cc(Cl)ccc1O/C=C/c1ccc(OCC(C)C)c(OC)c1</smiles>

b)<smiles>COc1ccc(C(O)C(O)CO)cc1OC</smiles><smiles>COc1cc(Cl)ccc1O</smiles><smiles>COc1cc(C(=O)OCC(=O)N[C@H](C(=O)O)C(=O)Nc2ccc(C(O)C(CO)Oc3ccc(C)cc3OC)cc2OC)ccc1O</smiles>

c)<smiles>COc1cc(C)ccc1OC(CO)C(O)c1ccc(O)cc1</smiles>

p-Hydroxyphenyl unit (H)<smiles>O=Cc1ccc(O)cc1</smiles>

p-Hydroxybenzaldehyde<smiles>O=C(O)c1ccc(O)cc1</smiles>

p-Hydroxybenzoic acid

d)

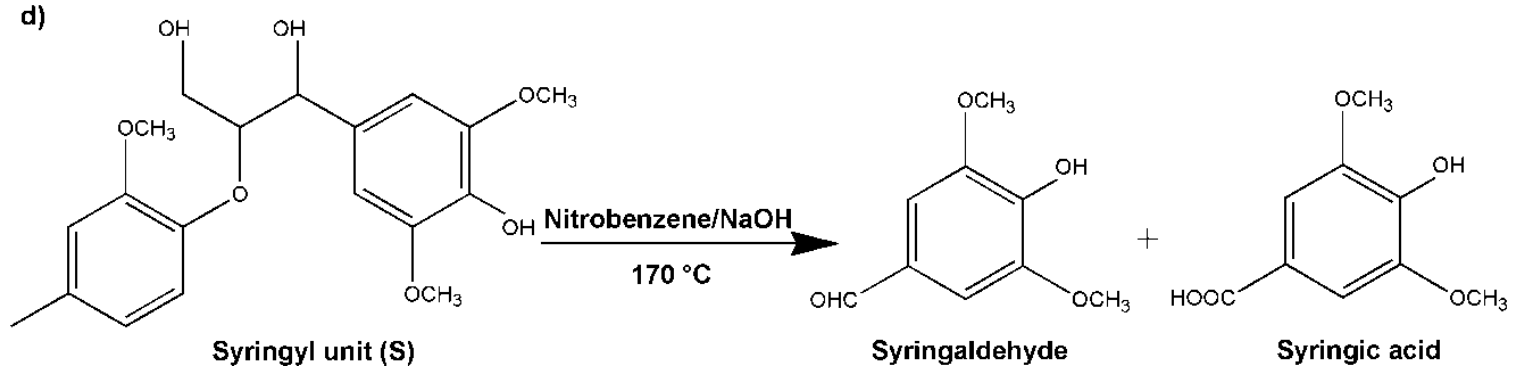

Fig. 6. a) The alkaline nitrobenzene oxidation reaction at $\beta-O-4$ lignin (Huang et al. 2019) and its oxidized products of b) guaiacyl (G), c) p-hydroxyphenyl (H), and d) syringyl (S) units (Jiang et al. 2019) 


\section{The Capability of $\mathrm{CH}$ Lignin in Lignin-based Applications}

Based on the findings of this research, the structural characteristics of lignin isolated from $\mathrm{CH}$ waste demonstrated a strong link to various alternative approaches in its potential applications. The presence of more G-type units, as well as higher phenolic content in $\mathrm{CH}$ lignin structure, confirmed that $\mathrm{CH}$ lignin can activate the free ring position, resulting in a more reactive potential active site in the polymerization process of phenolic resins, as determined by FTIR, NMR, and GPC analyses (Ibrahim et al. 2007; Aziz et al. 2019). At the same time, the presence of higher S-type units (C3 and C5 positions linked to methoxy group) in $\mathrm{CH}$ lignin may provide better reducing power ability and result in increased antioxidant activity (Latif et al. 2019). From the authors' previous research, higher phenolic contents can increase the hydrogen-donating ability and phenoxyl radical formation, which could be beneficial in metal corrosion inhibition (Sa'don et al. 2017b; Latif et al. 2019). Because lignin has been used in a broad area of applications (including corrosion inhibition and adhesives), high $T_{\mathrm{g}}$ values of $\mathrm{CH}$ lignin can be advantageous in lignin-based applications. That is why the current focus of this work is on the isolation of lignin from $\mathrm{CH}$ as a phenol substitute in lignin-phenol-glyoxal adhesives.

\section{CONCLUSIONS}

1. The isolation of coconut husk $(\mathrm{CH})$ lignin from different pulping processes (kraft, soda, and organosolv) produced different spectral characteristics and analytical results.

2. The molecular weight of alkaline lignin (kraft lignin (KL) and soda lignin (SL)) was found to be higher compared to organosolv lignin (OL), which is influenced by the repolymerization reaction.

3. During the alkaline oxidation process, the chemical composition analysis in $\mathrm{CH}$ lignin revealed that non-condensed $S$ units were degraded more preferentially in the organosolv pulping process than in the alkaline pulping process, which contains more non-condensed $\mathrm{G}$ units.

4. Alkaline $\mathrm{CH}$ lignin exhibited a better potential in a diversity of lignin-based applications, especially as phenol substitution in lignin-phenol-glyoxal wood adhesives due to the increased amount of phenolic-OH content, molecular weight, and thermal decomposition.

\section{ACKNOWLEDGEMENTS}

The authors gratefully acknowledge financial support from Universiti Sains Malaysia (Penang, Malaysia) through USM Research University Innovative (RUI) Grant 1001/PKIMIA/8011077. EA 4370 LERMAB is supported by the French National Research Agency through the ARBRE Laboratory of Excellence (ANR-12-LABXARBRE-01). Nur Hanis Abd Latif would like to express gratitude to the USM Fellowship scheme and Postgraduate Research Attachment (PGRA) program. 


\section{REFERENCES CITED}

Avelino, F., Oliveira, D. R., Mazzetto, S. E., and Lomonaco, D. (2019). "Poly(methyl methacrylate) films reinforced with coconut shell lignin fractions to enhance their UV-blocking, antioxidant and thermo-mechanical properties," Int. J. Biol. Macromol. 125, 171-180. DOI: 10.1016/j.ijbiomac.2018.12.043

Aziz, N. A., Latip, A. F. A., Peng, L. C., Latif, N. H. A., Brosse, N., Hashim, R., and Hussin, M. H. (2019). "Reinforced lignin-phenol-glyoxal (LPG) wood adhesives from coconut husk," Int. J. Biol. Macromol. 141, 185-196. DOI: 10.1016/j.ijbiomac.2019.08.255

Baker, D. A., and Rials, T. G. (2013). "Recent advances in low-cost carbon fiber manufacture from lignin," J. Appl. Polym. Sci. 130(2), 713-728. DOI: 10.1002/app.39273

Chua, K. Y., Azzahari, A. D., Abouloula, C. N., Sonsudin, F., Shahabudin, N., and Yahya, R. (2020). "Cellulose-based polymer electrolyte derived from waste coconut husk: Residual lignin as natural plastisizier,” J. Polym. Res. 27(5), 1-14. DOI: 10.1007/s10965-020-02110-8

Domínguez-Robles, J., Sánchez, R., Espinosa, E., Savy, D., Mazzei, P., Piccolo, A., and Rodríguez, A. (2017). "Isolation and characterization of Gramineae and Fabaceae soda lignins," Int. J. Mol. Sci. 18(2), article no. 327. DOI: 10.3390/ijms 18020327

El Hage, R., Brosse, N., Chrusciel, L., Sanchez, C., Sannigrahi, P., and Ragauskas, A. (2009). "Characterization of milled wood lignin and ethanol organosolv lignin from miscanthus," Polym. Degrad. Stab. 94(10), 1632-1638. DOI:

10.1016/j.polymdegradstab.2009.07.007

El Hage, R., Brosse, N., Sannigrahi, P., and Ragauskas, A. (2010). "Effects of process severity on the chemical structure of Miscanthus ethanol organosolv lignin," Polym. Degrad. Stab. 95(6), 997-1003. DOI: 10.1016/j.polymdegradstab.2010.03.012

Faris, A. H., Ibrahim, M. N. M., Rahim, A. A., Hussin, M. H., and Brosse, N. (2015). "Preparation and characterization of lignin polyols from the residues of oil palm empty fruit bunch," BioResources 10(4), 7339-7352. DOI: 10.15376/biores.10.4.7339-7352

Huang, J., Fu, S., and Gan, L. (2019). “Chemical modification of lignin,” in: Lignin Chemistry and Applications, J. Huang, S. Fu, and L. Gan (eds.), Elsevier, Amsterdam, Netherlands, pp. 51-78. DOI: 10.1016/B978-0-12-813941-7.00003-5

Hussin, M. H., Aziz, A. A., Iqbal, A., Ibrahim, M. N. M., and Latif, N. H. A. (2019). "Development and characterization novel bio-adhesive for wood using kenaf core (Hibiscus cannabinus) lignin and glyoxal," Int. J. Biol. Macromol. 122, 713-722. DOI: 10.1016/j.ijbiomac.2018.11.009

Hussin, M. H., Rahim, A. A., Ibrahim, M. N. M., and Brosse, N. (2013).

"Physicochemical characterization of alkaline and ethanol organosolv lignins from oil palm (Elaeis guineensis) fronds as phenol substitutes for green material applications," Ind. Crop. Prod. 49, 23-32. DOI: 10.1016/j.indcrop.2013.04.030

Hussin, M. H., Rahim, A. A., Ibrahim, M. N. M., Perrin, D., Yemloul, M., and Brosse, N. (2014). "Impact of catalytic oil palm fronds (OPF) pulping on organosolv lignin properties," Polym. Degrad. Stab. 109, 33-39. DOI:

10.1016/j.polymdegradstab.2014.06.016

Hussin, M. H., Samad, N. A., Latif, N. H. A., Rozuli, N. A., Yusoff, S. B., Gambier, F., and Brosse, N. (2018). "Production of oil palm (Elaeis guineensis) fronds lignin- 
derived non-toxic aldehyde for eco-friendly wood adhesive," Int. J. Biol. Macromol. 113, 1266-1272. DOI: 10.1016/j.ijbiomac.2018.03.048

Ibrahim, M. N. M., Zakaria, N., Sipaut, C. S., Sulaiman, O., and Hashim, R. (2011). "Chemical and thermal properties of lignins from oil palm biomass as a substitute for phenol in a phenol formaldehyde resin production," Carbohyd. Polym. 86(1), 112-

119. DOI: 10.1016/j.carbpol.2011.04.018

Ibrahim, M., Ghani, M. N., and Nen, N. (2007). "Formulation of lignin-phenolformaldehyde resins as wood adhesive," Malaysian J. Anal. Sci. 11(1), 213-218.

Israel, A. U., Ogali, R. E., Akaranta, O., and Obot, I. B. (2011). "Extraction and characterization of coconut (Cocos nucifera L.) coir dust," Songklanakarin J. Sci. Technol. 33(6), 717-724.

Jiang, B., Zhang, Y., Zhao, H., Guo, T., Wu, W., and Jin, Y. (2019). "Dataset on structure-antioxidant activity relationship of active oxygen catalytic lignin and lignincarbohydrate complex," Data in Brief 25, article ID 104413. DOI: 10.1016/j.dib.2019.104413

Jincy, J. P., Ravindranath, A. D., and Sarma, U. S. (2015). "Ecofriendly organosolv process for pulping of tender coconut fibre," CORD 31(1), 13-23. DOI: 10.37833/cord.v31i1.64

Johari, K., Saman, N., Song, S., Chin, C. S., Kong, H., and Mat, H. (2016). “Adsorption enhancement of elemental mercury by various surface modified coconut husk as ecofriendly low-cost adsorbents," Int. Biodeter. Biodegr. 109, 45-52. DOI: 10.1016/j.ibiod.2016.01.004

Kaewdang, O., and Benjakul, S. (2015). "Effect of ethanolic extract of coconut husk on gel properties of gelatin from swim bladder of yellowfin tuna," LWT-Food Sci. Technol. 62(2), 955-961. DOI: 10.1016/j.lwt.2015.02.006

Kumar, S. N. (2011). "Variability in coconut (Cocos nucifera L.) germplasm and hybrids for fatty acid profile of oil," J. Agr. Food Chem. 59(24), 13050-13058. DOI: 10.1021/jf203182d

Latif, N. H. A., Rahim, A. A., Brosse, N., and Hussin, M. H. (2019). "The structural characterization and antioxidant properties of oil palm fronds lignin incorporated with p-hydroxyacetophenone," Int. J. Biol. Macromol. 130, 947-957. DOI: 10.1016/j.ijbiomac.2019.03.032

Lertwattanaruk, P., and Suntijitto, A. (2015). "Properties of natural fiber cement materials containing coconut coir and oil palm fibers for residential building applications," Constr. Build. Mater. 94, 664-669. DOI: 10.1016/j.conbuildmat.2015.07.154

Luo, X., Xiao, Y., Wu, Q., and Zeng, J. (2018). "Development of high-performance biodegradable rigid polyurethane foams using all bioresource-based polyols: Lignin and soy oil-derived polyols," Int. J. Biol. Macromol. 115, 786-791. DOI: 10.1016/j.ijbiomac.2018.04.126

Mahidin, M. U. (2020). "Press release supply and utilization accounts selected agricultural commodities Malaysia 2015-2019," (https://www.dosm.gov.my/v1/index.php?r=column/pdfPrev\&id=OTM1TDMzS1IvY m5mU1JiU1Fwekt3UT09), Accessed 17 Feb 2021.

Ngadi, N., Jusoh, M., Rahman, R. A., and Mohamad, Z. (2015). "Synthesis and application of carbon cryogel beads using coconut husk for dye removal," Appl. Mech. Mater. 695, 183-186. DOI: 10.4028/www.scientific.net/AMM.695.183 
Obame, S. N., Ziegler-Devin, I., Safou-Tchima, R., and Brosse, N. (2019). "Homolytic and heterolytic cleavage of $\beta$-ether linkages in hardwood lignin by steam explosion," J. Agr. Food Chem. 67(21), 5989-5996. DOI: 10.1021/acs.jafc.9b01744

Privas, E., and Navard, P. (2013). "Preparation, processing and properties of lignosulfonate-flax composite boards," Carbohyd. Polym. 93(1), 300-306. DOI: 10.1016/j.carbpol.2012.04.060

Qingqing, M., Shen, X., Liu, H., and Han, B. (2019). "Selectively transform lignin into value-added chemicals," Chinese Chem. Lett. 30(1), 15-24. DOI: 10.1016/j.cclet.2018.04.032

Ram, M., and Mondal, M. K. (2018). "Comparative study of native and impregnated coconut husk with pulp and paper industry waste water for fuel production," Energy 156, 122-131. DOI: 10.1016/j.energy.2018.05.102

Sa'don, N. A., Rahim, A. A., and Hussin, M. H. (2017a). "The effect of $p$-nitrophenol toward the structural characteristics and antioxidant activity of oil palm fronds (OPF) lignin polymers," Int. J. Biol. Macromol. 98, 701-708. DOI:

10.1016/j.ijbiomac.2017.01.137

Sa'don, N. A., Rahim, A. A., Ibrahim, M. N. M., Brosse, N., and Hussin, M. H. (2017b). "Modification of oil palm fronds lignin by incorporation of m-cresol for improving structural and antioxidant properties," Int. J. Biol. Macromol. 104(Part A), 251-260. DOI: 10.1016/j.ijbiomac.2017.06.038

Saari, N. F. N., Samsudin, D., Wahab, N. M. A., Majid, N. A., Daik, R., and Ishak, M. A. M. (2016). "Preparation and characterization of lignin from Malaysian coconut coir husk as a potential precursor in phenol-formaldehyde (phenolic) resins for plastic industry," Adv. Mater. Res. 1133, 583-587. DOI:

10.4028/www.scientific.net/AMR.1133.583

Sangian, H. F., and Widjaja, A. (2018). "The effect of alkaline concentration on coconut husk crystallinity and the yield of sugars released," IOP Conf. Ser-Mat. Sci. 306(1), Article ID 012046. DOI: 10.1088/1757-899X/306/1/012046

Sluiter, A., Hames, B., Ruiz, R., Scarlata, C., Sluiter, J., and Templeton, D. (2005a). "Determination of ash in biomass - laboratory analytical procedure (LAP)," Technical Report NREL/TP-510-42622, National Renewable Energy Laboratory (NREL), USA.

Sluiter, A., Ruiz, R., Scarlata, C., Sluiter, J., and Templeton, D. (2005b). "Determination of extractives in biomass - laboratory analytical procedure (LAP)," Technical Report NREL/TP-510-42619, National Renewable Energy Laboratory (NREL), USA.

Sluiter, A., Hames, B., Hyman, D., Payne, C., Ruiz, R., Scarlata, C., Sluiter, J., Templeton, D., and Wolfe, J. (2008a). "Determination of total solids in biomass and total dissolved solids in liquid process samples - laboratory analytical procedure (LAP)," Technical Report NREL/TP-510-42621, National Renewable Energy Laboratory (NREL), USA.

Sluiter, A., Hames, B., Ruiz, R., Scarlata, C., Sluiter, J., Templeton, D., and Crocker, D. (2008b). "Determination of structural carbohydrates and lignin in biomass laboratory analytical procedure (LAP)," Technical Report NREL/TP-510-42618, National Renewable Energy Laboratory (NREL), USA.

Spiridon, I., Leluk, K., Resmerita, A. M., and Darie, R. N. (2015). "Evaluation of PLAlignin bioplastics properties before and after accelerated weathering," Compos. Part B-Eng. 69, 342-349. DOI: 10.1016/j.compositesb.2014.10.006 
Tahri, I., Ziegler-Devin, I., Ruelle, J., Segovia, C., and Brosse, N. (2016). "Extraction and characterization of fibers from palm tree," BioResources 11(3), 7016-7025. DOI: 10.15376/biores.11.3.7016-7025

TAPPI T203 cm-09 (2009). “Alpha-, beta- and gamma-cellulose in pulp,” TAPPI Press, Atlanta, GA, USA.

Tribot, A., Amer, G., Alio, M. A., de Baynast, H., Delattre, C., Pons, A., Mathias, J-D., Callois, J-M., Vial, C., Michaud, P., and Dussap, C-G. (2019). "Wood-lignin: Supply, extraction processes and use as bio-based material," Eur. Polym. J. 112, 228-240. DOI: $10.1016 /$ j.eurpolymj.2019.01.007

Upton, B. M., and Kasko, A. M. (2016). "Strategies for the conversion of lignin to highvalue polymeric materials: Review and prespective," Chem. Rev. 116(4), 2275-2306. DOI: 10.1021/acs.chemrev.5b00345

van Dam, J. E. G., van den Oever, M. J. A., Teunissen, W., Keijsers, E. R. P., and Peralta, A. G. (2004). "Process for production of high density/high performance binderless boards from whole coconut husk: Part 1: Lignin as intrinsic thermosetting binder resin," Ind. Crop. Prod. 19(3), 207-216. DOI: 10.1016/j.indcrop.2003.10.003

Wang, S., Dai, G., Yang, H., and Luo, Z. (2017). "Lignocellulosic biomass pyrolysis mechanism: A state-of-the-art review," Prog. Energ. Combust. Sci. 62, 33-86. DOI: 10.1016/j.pecs.2017.05.004

Watkins, D., Nuruddin, M., Hosur, M., Tcherbi-Narteh, A., and Jeelani, S. (2015). "Extraction and characterization of lignin from different biomass resources," $J$. Mater. Res. Technol. 4(1), 26-32. DOI: 10.1016/j.jmrt.2014.10.009

Xu, G., Yang, J.-h., Mao, H.-h., and Yun, Z. (2011). "Pulping black liquor used directly as a green and effective source for neat oil and as an emulsifier of catalytic cracking heavy oil," Chem. Technol. Fuels Oils 47(4), 283-291. DOI: 10.1007/s10553-0110297-9

Zakaria, S. M., Idris, A., and Alias, Y. (2017). "Lignin extraction from coconut shell using aprotic ionic liquids," BioResources 12(3), 5749-5774. DOI: 10.15376/biores.12.3.5749-5774

Article submitted: July 21, 2021; Peer review completed: October 9, 2021; Revised version received and accepted: November 5, 2021; Published: November 24, 2021. DOI: 10.15376/biores.17.1.469-491 